\title{
Self-tensioning long-span T-shaped spruce and oak web floors with a CLT upper flange. An experimental approach
}

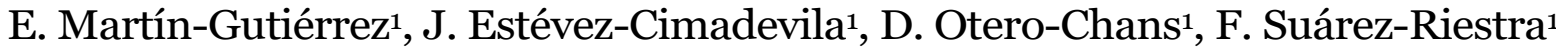 \\ (1) Department of Architectural, Civil and Aeronautical Building Structures, Universidade da Coruña, \\ Campus A Zapateira, 15071, A Coruña, Spain.
}

Corresponding author: emilio.martin@udc.es (Emilio Martín-Gutiérrez)

ORCID:https://orcid.org/0000-0001-7464-4288 (Emilio Martín-Gutiérrez) https://orcid.org/0000-0002-8460-2097 (Javier Estévez-Cimadevila) https://orcid.org/0000-0003-1738-252X (Dolores Otero-Chans) https://orcid.org/0000-0002-8839-5611 (Félix Suárez-Riestra)

\begin{abstract}
A device is described that makes it possible to automatically apply a post-tensioning force on deflected elements in response to applied gravitational loads. The behaviour of transverse T-section beams is analysed. They are composed of a laminated oak or spruce rib and a cross-laminated timber upper flange (CLT). Fourteen $9 \mathrm{~m}$ span beams were subjected to a four-point bending test until failure. Six of the beams include the self-tensioning system to comparatively verify its efficacy. A numerical analysis model was also developed to describe the behaviour of the proposed device, considering a non-linear regime and interaction between moving parts. The post-tensioned elements attained a noteworthy increase in their final load in comparison with the unreinforced beams. On the other hand, in their service situation they showed a major reduction in their average relative deflection. The conclusions indicate that there is a relevant improvement in their behaviour under deformation, even with a reduced structural width. This improvement is highly useful in long-span wooden floors, where restricted deformation is usually the predominant dimensioning criterion to prevent damage to partition walls.
\end{abstract}

HIGHLIGHTS:

- A self-tensioned system was developed to design small depth and long-span timber floors.

- The device automatically apply a post-tensioned force in response to gravitational loads.

- The T-shaped floors showed a noticeable reduction in their average relative deflection.

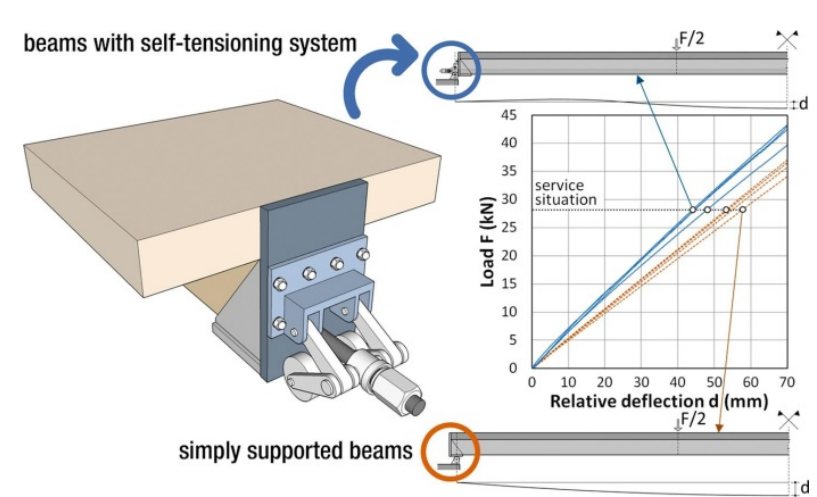




\section{Introduction}

\subsection{Brief review of the state of the art}

There is no doubt that wood has been one of the most widely-used building materials throughout history. This is due to many reasons, such as its easy workability, high strength-to-weight ratio, and attractive aesthetic properties. In recent decades its interest for industry has increased greatly, largely because of its extraordinary environmental properties: it captures and stores carbon dioxide and does not consume much energy when subjected to transformation, and it is almost completely reusable.

On the other hand, several disadvantages make it less competitive in certain fields. As it is a naturally occurring material its rigidity and strength values are variable to a certain degree and both are highly sensitive to the presence of defects (knots, cracks and fibre deviations, etc.) as well as to external conditions during growth. These drawbacks may be minimised significantly by using engineered wood products such glued laminated timber. These are now available in the form of a large number of solutions, qualities and sizes. However, their use is still restricted in the case of long span elements or heavy load requirements, at least in comparison with other alternatives in steel or concrete. This is why multiple reinforcing systems have been developed (most of them for flexural reinforcement), in order to improve mechanical behaviour and to reduce the dimensions of structural elements. Research has involved the inclusion of metal additions (steel bars, stranded cables and steel or aluminium plates), or shaped elements that use advanced composite materials such as aramid, glass or carbon fibre.

Gentile et al. [1] reported a noticeable strength enhancement in the flexural behaviour of sawn Douglas spruce timber beams, using glass fibre reinforced polymer (GFRP) bars bonded in grooves near the bottom of the section. Isaa and Kmeid [2] describe similar effects in glulam beams made with sawn lumber laminations, externally reinforced by either a steel plate or carbon fibre reinforced polymer (CFRP). Raftery and Harte [3] used GFRP plates to reinforce glulam beams made with low-grade Irish Sitka spruce. The plates were bonded to the soffit of the glulam with an epoxy adhesive. A thin sacrificial lamination was added to some specimens to improve their fire resistance. Although Glisovic et al. [4] also reinforced glulam beams made from spruce timber, they used CFRP plates bonded to them with an epoxy resin. In this case the plates were internal as well as external and took different configurations, although they were always on the lower part of beams. Yang et al. [5] compared a range of reinforcement methods in glulam beams made from Douglas spruce. They used GFRP bars and plates, CFRP plates and steel bars as reinforcement in their study. These elements were bonded to the inside of grooves that were either close to the base of the section or were both in the top and bottom. Soriano et al. [6] studied the behaviour of glulam beams constructed with seven laminates of which the three central ones were lower category. They used steel bars as reinforcements in their study, bonded using single component polyurethane adhesives to the inside of grooves arranged symmetrically to the neutral axis. 
Corradi and Borri [7] used a singular approach with single cross-section glass fibre pultruted elements attached to the compressed face of white spruce or chestnut wood beams.

Additionally, wood usually presents ductile failure when under compression and brittle fracture in tension, with a limiting value that is highly sensitive to the presence of natural defects. To prevent failures of this type many published studies also include pre- or post-tensioning techniques. These add eccentric forces with the aim of annulling or reducing maximum tensile stress and thereby limiting flexure deformations.

Within the category of bonded active reinforcements, Guan et al. [8] numerically and experimentally analysed the effect of using prestressed GFRP tendons as bonded reinforcements between the two lowest layers of glulam beams. Borri and Corradi [9] studied the external strengthening of several timber beams (oak and white spruce) with high strength steel cords bonded to the tension area with epoxy systems. Likewise, De Luca and Marano [10] suggest reinforcement composed of two steel bars arranged symmetrically in longitudinal slots in the top and bottom faces, including pretensioning of the lower bar. McConnell et al. [11] also reinforced glulam beams made with European spruce by post-tensing them. They used steel tendons housed in longitudinal slots near the soffit for this, unbonded in some test pieces and bonded by means of epoxy adhesive injection in the other cases.

In any case, reinforcement systems using bonded elements often give rise to problems at the ends of beams due to the high concentration of stresses which occur there [12]. Due to these effects other reinforcement techniques have been developed which use non-adherent tendons. Unbonded post-tensioned timber frames were analysed by Van Beerschoten et al. [13] under gravity loading. The behaviour of these structures has also been studied under horizontal forces [14]. Advanced damping systems have also been added to these devices, aiding dissipation of the energy arising from dynamic actions [15].

\subsection{Description of the system}

This paper describes a new $\mathrm{T}$ cross-section wooden floor system with unbonded post-tensioning tendons. This system has been patented, and it was initially developed to resolve long spans, in which post- tensioning is self-adjusting depending on the loads applied at any given time. This design has been subjected to several previous analytical studies [16-18], and these are now completed by an experimental study to validate its performance.

Beams supported at two places equipped with a special device connected to an internal tendon are described (Fig. 1). This device is composed of simple articulated elements which transform the vertical displacements caused by gravitational effects into lengthening of the tendon, which therefore withstands a tensile force. This gives rise to eccentric posttensioning that depends on the load in question, which in turn generates a negative bending moment. This effect leads to a redistribution of moments that significantly reduces tension stresses in the web and relative deformations among the different cross-sections of the beam. 


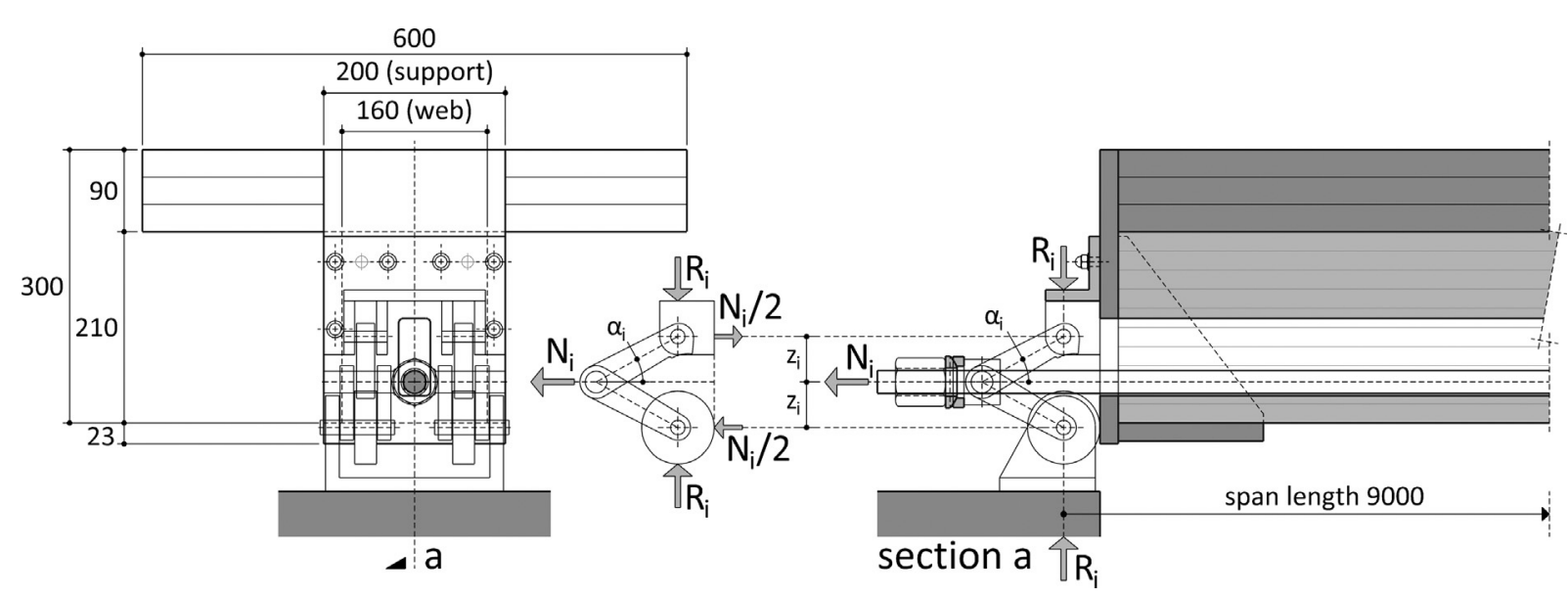

Fig. 1. Geometric sketch of the self-tensioning device (dimensions in $\mathrm{mm}$ ).

\section{Materials and methods}

\subsection{Timber elements}

Glulam webs are made of Norway Spruce (Picea abies L. Karst), strength class GL28h (EN 14080:2013) [19], or European Oak (Quercus robur L.), visual grade LS13 (DIN 4074-5:2008-12 [20], European Technical Approval ETA-13/0642 [21]). Their mechanical properties are listed in Table 1 , according to standards in the first case and manufacturer specifications in the second case.

Table 1: Glulam specifications.

\begin{tabular}{llll}
\hline Parameter & & Spruce & Oak \\
\hline Bending strength, characteristic value (MPa) & $f_{m, k}$ & 28 & 33 \\
Tensile strength parallel to the grain, characteristic value (MPa) & $f_{t, o, k}$ & 22.3 & 23 \\
Tensile strength perpendicular to the grain, characteristic value (MPa) & $f_{t, 90, k}$ & 0.5 & 0.6 \\
Compression strength parallel to the grain, characteristic value (MPa) & $f_{c, o, k}$ & 28 & 45 \\
Compression strength perpendicular to the grain, characteristic value (MPa) & $f_{c, 90, k}$ & 2.5 & 8 \\
Shear strength, characteristic value (Mpa) & $f_{v, k}$ & 3.5 & 4 \\
Modulus of elasticity parallel to the grain, average value (MPa) & $E_{o, \text { mean }}$ & 12,600 & 14,400 \\
Modulus of elasticity parallel to the grain, 5\% fractile value (MPa) & $E_{o, \text { o5 }}$ & 10,500 & 12,000 \\
Modulus of elasticity perpendicular to the grain, average value (MPa) & $E_{90, \text { mean }}$ & 300 & 800 \\
Modulus of elasticity perpendicular to the grain, 5\% fractile value (MPa) & $E_{90,05}$ & 250 & 660 \\
Shear modulus of elasticity, average value (MPa) & $G_{m e a n}$ & 650 & 850 \\
Shear modulus of elasticity, 5\% fractile value (MPa) & $G_{o 5}$ & 54 & 700 \\
Density, characteristic value (kg/m3) & $\rho_{k}$ & 425 & 690 \\
\hline
\end{tabular}

Upper flanges are made with $90 \mathrm{~mm}$ thick type L3S CLT panels composed of three $30 \mathrm{~mm}$ spruce (Picea abies L. Karst) layers, strength class C24 (EN 338:2009 [22], ETA-14/0349 [23]). Their mechanical characteristics are shown in Table 2. In all cases, webs were made with a cross-section of $160 \times$ $210 \mathrm{~mm}$, and the upper flanges with $600 \times 90 \mathrm{~mm}$, as shown in Fig. 1 . 
Table 2: CLT manufacturer specifications.

\begin{tabular}{lll}
\hline Parameter & & Value \\
\hline Bending strength, characteristic value (MPa) & $f_{m, k}$ & 24 \\
Tensile strength parallel to the grain, characteristic value (MPa) & $f_{t, o, k}$ & 14 \\
Compression strength parallel to the grain, characteristic value (MPa) & $f_{c, o, k}$ & 22 \\
Shear strength parallel to the grain, characteristic value (Mpa) & $f_{v, o, k}$ & 2.5 \\
Modulus of elasticity parallel to the grain, average value (MPa) & $E_{o, \text { mean }}$ & 12,500 \\
Shear modulus of elasticity, average value (MPa) & $G_{m e a n}$ & 460 \\
Density, characteristic value (kg/m3) & $\rho_{k}$ & 420 \\
\hline
\end{tabular}

\subsection{Steel elements}

In each piece the connection between the web and upper flange is by means of perforated hot-galvanised steel plates, grade S235 (EN 1993-1-1:2005 [24], yield strength $f_{y}=235 \mathrm{MPa}$, ultimate tensile strength $f_{u}=360 \mathrm{MPa}$ ), measuring $410 \times 80 \times 4 \mathrm{~mm}$ and drilled with circular $10 \mathrm{~mm}$ diameter holes 5 mm apart (Fig. 2). The plates and wooden elements are bonded using a 2component polyurethane adhesive (Loctite Purbond CR 421).

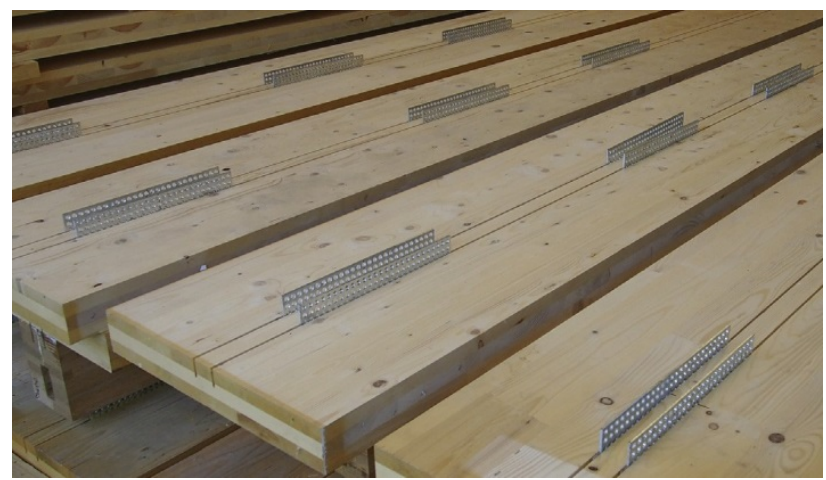

Fig. 2. Discontinuous connections on the top plank (separations between plates are described in Fig. 5).

Self-tensioning is carried out using Dywidag-type threaded bar with a nominal diameter of $26.5 \mathrm{~mm}$ and characterized as grade Y105OH (prEN 10138-4 [25], yield strength $f_{p o .1 k}=950 \mathrm{MPa}$, ultimate tensile strength $f_{p k}=$ $1050 \mathrm{MPa}$ ). The area of the tendon was determined to limit its lengthening and the subsequent descent of the supports.

Previous studies using FEM analysis made it possible to define sui- table dimensions and steel qualities for the supports and self-tensioning systems for the expected stresses at ultimate load (Fig. 3). The head and base plates as well as the side rigidising corbels are therefore in class S275 steel (EN 1993-11:2005 [24], $\left.f_{y}=275 \mathrm{MPa}, f_{u}=410 \mathrm{MPa}\right)$. On the other hand, the articulated parts and wheels are in class S690 steel (EN 10027-1:2005 [26], $f_{y}=690$ $\left.\mathrm{MPa}, f_{u}=750 \mathrm{MPa}\right)$, while the plates connecting both sets are of intermediate quality, S355 (EN 1993-1-1:2005 [24], $f_{y}=355 \mathrm{MPa}, f_{u}=470 \mathrm{MPa}$ ). It must be pointed out that the whole device was broadly oversized with the aim of carrying out tests to breakage using different configurations, so that load values averaging three times service ones were reached. 


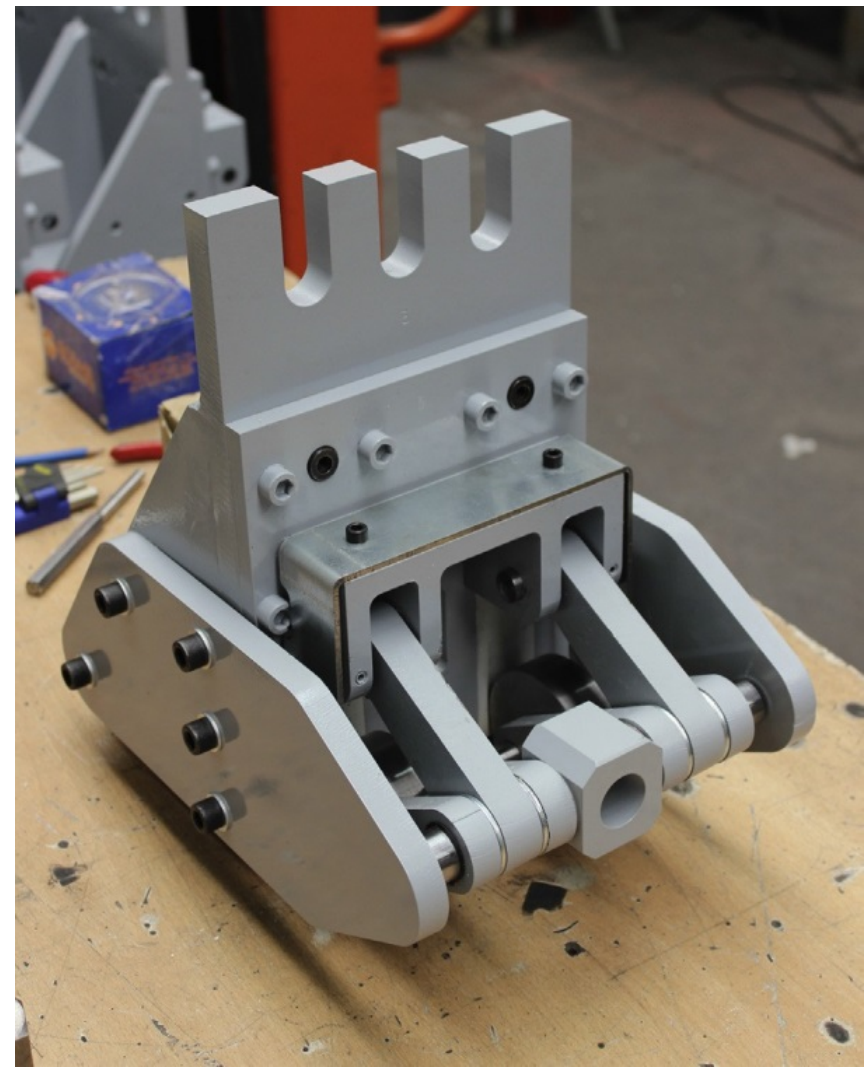

Fig. 3. Support composed of steel elements

\subsection{Preliminary tests}

In order to find the global modulus of elasticity in bending the wood used, a series of four-point bending non-destructive tests were carried out, in all cases with a span of $9000 \mathrm{~mm}$. A total of 12 specimens were tested: 4 Norway Spruce webs with a $160 \times 210 \mathrm{~mm}$ cross-section, 4 European Oak webs with identical dimensions and 4 CLT 600x90 mm cross-section upper flanges.

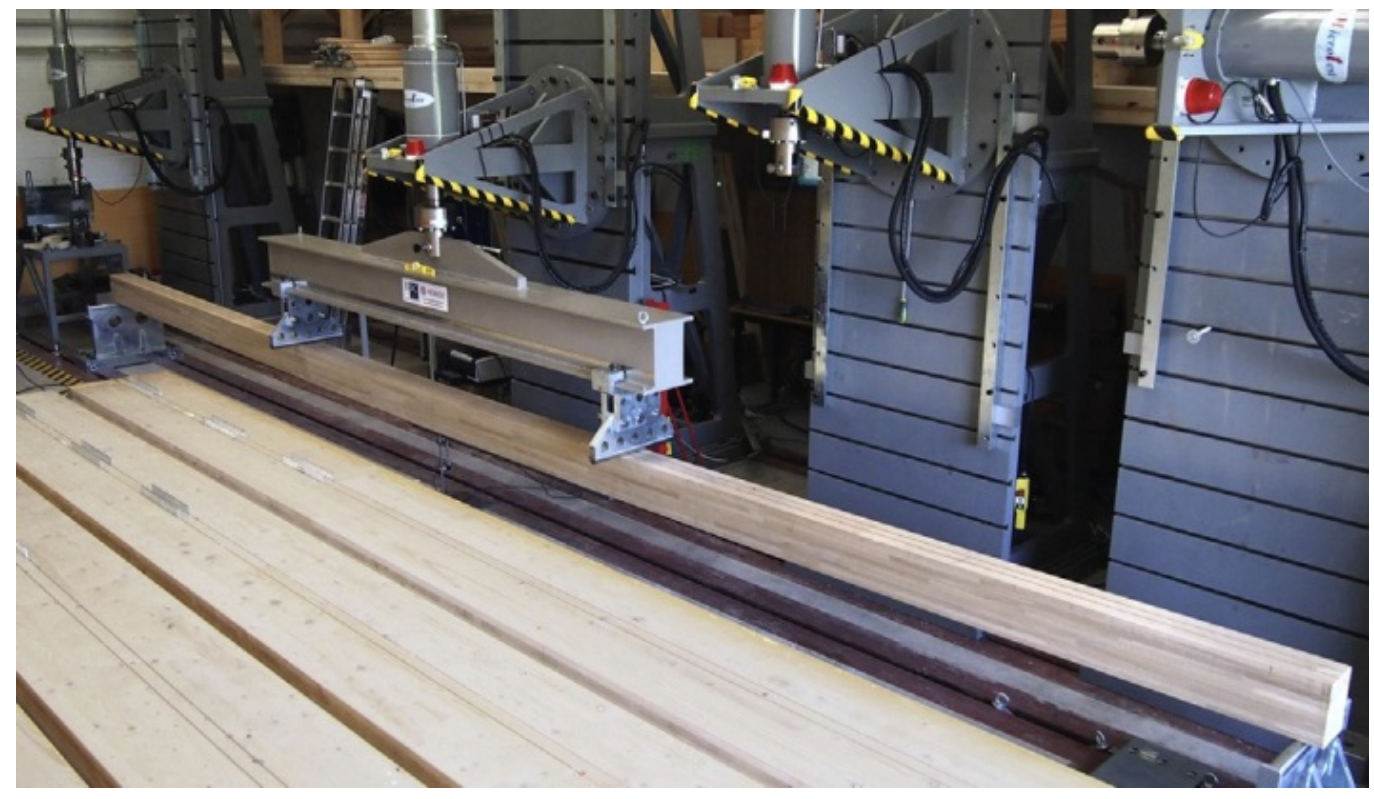

Fig. 4. Preliminary bending test (European Oak web). 
The tests were performed using a hydraulic Microtest model PB2-F/ 600 machine, with a maximum capacity of $600 \mathrm{kN}$ (Fig. 4). Vertical displacements in the central section were measured using a Schreiber SM260.100.2.ST inductive displacement transducer with $100 \mathrm{~mm}$ of standard measurement stroke. The modulus of elasticity in bending was calculated using Eq. (1), according to standard EN 408:2010 + A1:2012 [27]

$$
E_{m, g}=\frac{3 a L^{2}-4 a^{3}}{2 b h^{2}\left(2 \frac{w_{2}-w_{1}}{F_{2}-F_{1}}-\frac{6 a}{5 G b h}\right)}
$$

where

$a$ is the distance between a loading position and the nearest support;

$L$ is the span; $\mathrm{b}$ and $\mathrm{h}$ are dimensions of the cross section of the beam;

$\left(F_{2}-F_{1}\right)$ is the increment of load on the straight line portion of the load-deformation curve (defined as from $10 \%$ to $40 \%$ of maximum estimated load);

$\left(w_{2}-w_{1}\right)$ is the increase in the deformation of the same part;

$G$ is the shear modulus, estimated as E/16.

\subsection{Test setup}

A total of $14 \mathrm{~T}$ cross-section beams were tested, composed of a $160 \times 210 \mathrm{~mm}$ web and a $600 \times 90 \mathrm{~mm}$ CLT upper flange, giving a total depth of $300 \mathrm{~mm}$ (Fig. 5a). The distance between supports was $9000 \mathrm{~mm}$ in all cases. The pieces were subjected to a four-point bending test, using the same equipment described in the previous section. Lateral bracing was provided in the sections where load was applied to prevent lateral instability in the flexed beams. Nevertheless, it was found that working of this bracing was not triggered at any time during the series of experiments.

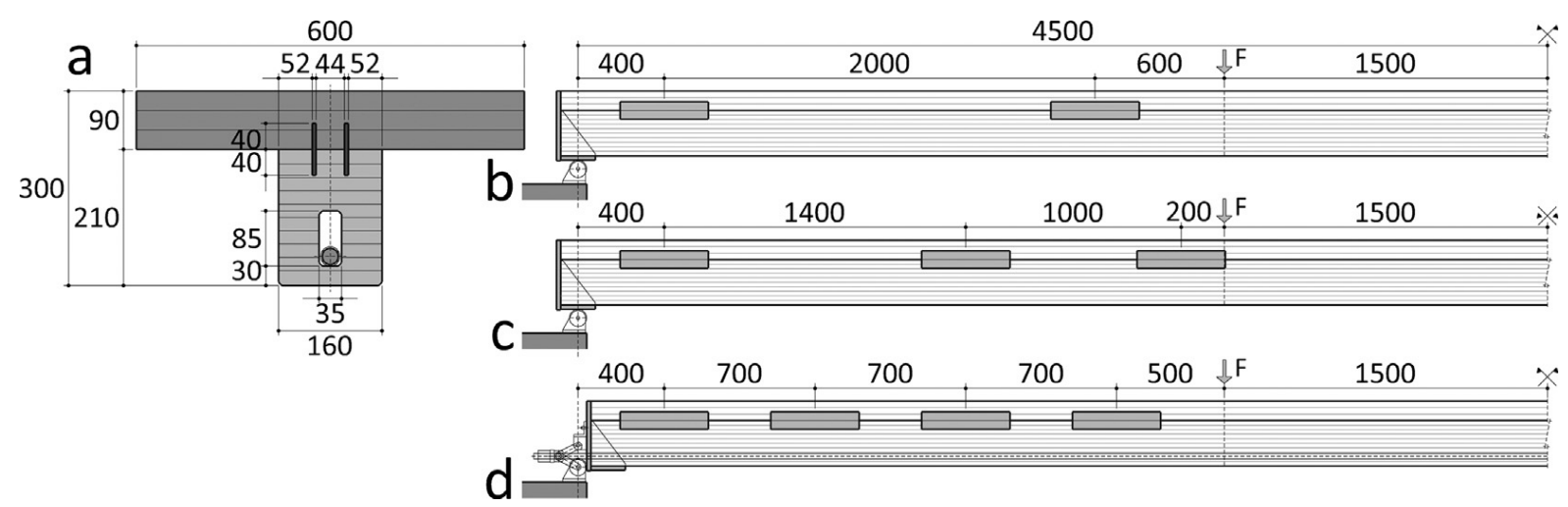

Fig. 5. Cross-section and arrangements of perforated connection plates (dimensions in $\mathrm{mm}$ ).

The initial approach was to test 8 pieces for each timber product. However, the first two beams showed inadequate results, due to an excessive friction in the connecting rods of the self-tensioning device. Consequently, the results were discarded, and the device improved with Teflon washers. The paper presents the study carried out with the remaining 14 beams, 6 made with Norway Spruce webs and 8 made using European Oak webs. 2 beams with Norway Spruce web and 4 with European Oak web were tested to breakage with the self-tensioning device. The others (4 with Norway Spruce web and 4 
with European Oak web) were tested without the device, with the aim of evaluating its efficacy by comparison. In each case, the distance between the plates connecting the web and the flange was adjusted to the expected stresses at ultimate load, according to previous studies conducted by numerical analysis. In this sense, the objective was to achieve a reliable connection throughout the test. The solutions shown in Fig. 5b and c correspond respectively with the Norway Spruce and European Oak beams tested without the self-tensioning device. In the tests in which the device was used (Fig. 6), the connection plates were arranged in the pattern shown in Fig. 5d, regardless of the type of wood used in the web, due to the expected increase in load capacity.

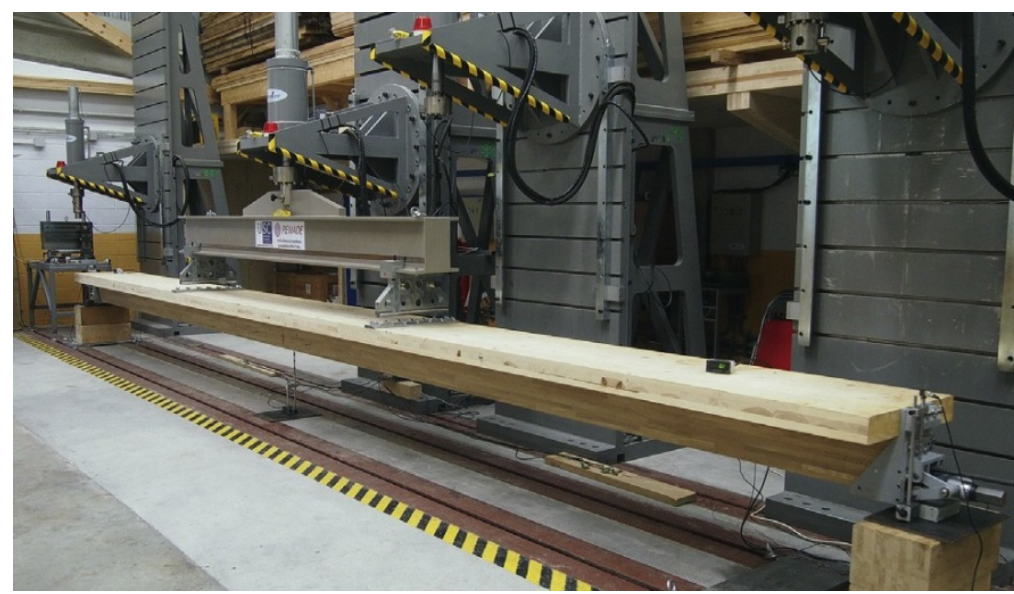

Fig. 6. Four-point bending test in the configuration with the self-tensioning device.

The web of the self-tensioning beams was made with an interior lengthwise groove with a cross-section of $35 \times 85 \mathrm{~mm}$ to hold the threaded $26.5 \mathrm{~mm}$ diameter bar. In all cases this bar was anchored in the central region of the beam by epoxy adhesive injected into the groove over a length of approx. 150 $\mathrm{mm}$. This technique makes it possible to balance possible differences in the horizontal forces originating at both supports under asymmetrical loading conditions [1] ].

The self-tensioning system was set at an initial zo value of $30 \mathrm{~mm}$ (Fig. 1, ao $\left.=16.94^{\circ}\right)$. Previous studies indicated that this configuration could display notable efficacy in transforming slight descents of the supports into a significant self-tensioning force [18].

2 Shreider SM260.60.2.ST inductive displacement transducers were added to the laboratory equipment described above to measure descents at the supports. Extensometric bands were also attached close to the ends of the tensioning bar to measure strain of the same and thereby deduce the amount of self-tensioning produced at each load level.

\section{Results and discussion}

\subsection{Modulus of elasticity of the timber products}

Table 3 shows the overall MOE (modulus of elasticity) value obtained for each one of the timber products used in the preliminary series of experiments. 
It is important to underline the notable decrease in rigidity found in comparison with the classification values or those supplied by the manufacturers. Other authors detected even greater differences [11].

Table 3: Modulus of elasticity parallel to the grain.

\begin{tabular}{lcccccc}
\hline Timber & \multicolumn{2}{c}{ Geometrical parameters } & \multicolumn{2}{c}{ Experimental values } & Classification values & Loss \\
\cline { 2 - 7 } & $\begin{array}{c}\text { Cross section } \\
(\mathrm{mm})\end{array}$ & Span $(\mathrm{mm})$ & Eo,mean,ex (Mpa) & Standard deviation & Eo,mean (Mpa) & $(\%)$ \\
\hline Spruce & $160 \times 210$ & 9000 & 10,875 & 412 & 12,600 & 13.69 \\
Oak & $160 \times 210$ & 9000 & 11,910 & 238 & 14,400 & 17.29 \\
CLT & $600 \times 90$ & 9000 & 11,748 & 908 & 12,500 & 6.02 \\
\hline
\end{tabular}

\subsection{The rigidity of the floor system}

As was pointed out above, not only the vertical displacement at the midpoint of the beam was measured in the pieces equipped with the self-tensioning device, as this was also measured at the seat of the supports (Table 4). Relative deflections were therefore determined throughout the test (as the difference between the displacements at the midpoint and at the supports). This parameter is the most important when considering the criteria of constructive element integrity to control the deformability of the structural system. Fig. 7 compares the behaviour of the floor made using European Oak webs with and without the self-tensioning system. It shows the deflections corresponding to 20 and $28 \mathrm{kN}$. The first value corresponds to a combination of quasi-permanent actions (considering a factor of $\Psi_{2}=0.6$ ), while the second corresponds to the total uniform distributed load in the service situation of $7 \mathrm{kN} / \mathrm{m} 2$ : a permanent load of $2 \mathrm{kN} / \mathrm{m} 2$, corresponding to the self-weight of the structural system and its coating, and a variable load of 5 $\mathrm{kN} / \mathrm{m} 2$ corresponding to obstacle-free commercial and public areas (EN 1991-1-1:2002) [28]. Under the quasi-permanent conditions the selftensioning device reduced the average relative deflection from 38.85 to $31.53 \mathrm{~mm}$ (18.82\%) when European Oak web was used, and from 41.61 to $30.43 \mathrm{~mm}$ (26.88\%) with Norway Spruce webs. Under the total load the reduction was from 55.09 to $45.01 \mathrm{~mm}(18.32 \%)$ with European Oak webs, and from 58.21 to $43.21 \mathrm{~mm}(25.78 \%)$ with Norway Spruce webs. These reductions are relevant to prevent damage to partition walls.

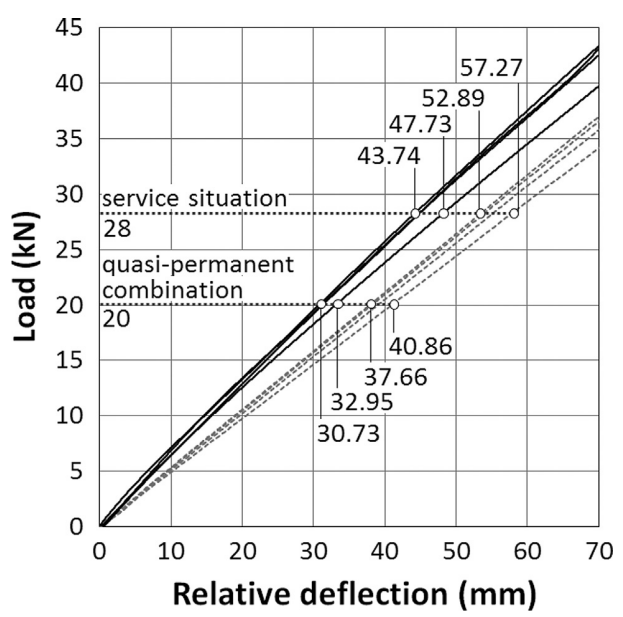

Fig. 7. Comparison of load - relative deflection curves (oak webs). Solid lines: beams with selftensioning system. Dashed lines: beams without self-tensioning. 
E. Martín-Gutiérrez, J. Estévez-Cimadevila, D. Otero-Chans, F. Suárez-Riestra Self-tensioning long-span T-shaped spruce and oak web floors with a CLT upper flange.

Table 4: Results of the experimental campaign.

\begin{tabular}{|c|c|c|c|c|c|c|c|c|c|c|}
\hline \multirow[t]{3}{*}{ Reference } & \multicolumn{2}{|c|}{ Total load: $20 \mathrm{kN}$} & \multicolumn{6}{|c|}{ Total load: $28 \mathrm{kN}$} & \multicolumn{2}{|c|}{ Ultimate load $(\mathrm{kN})$} \\
\hline & \multirow[t]{2}{*}{$\begin{array}{l}\text { Deflection } \\
\text { at midpoint } \\
(\mathrm{mm})\end{array}$} & \multirow[t]{2}{*}{$\begin{array}{l}\text { Seat of the } \\
\text { supports } \\
(\mathrm{mm})\end{array}$} & \multicolumn{2}{|c|}{$\begin{array}{l}\text { Relative } \\
\text { deflection } \\
(\mathrm{mm})\end{array}$} & \multirow[t]{2}{*}{$\begin{array}{l}\text { Deflection } \\
\text { at midpoint } \\
(\mathrm{mm})\end{array}$} & \multirow[t]{2}{*}{$\begin{array}{l}\text { Seat of the } \\
\text { supports } \\
(\mathrm{mm})\end{array}$} & \multicolumn{2}{|c|}{$\begin{array}{l}\text { Relative } \\
\text { deflection } \\
(\mathrm{mm})\end{array}$} & & \multirow[b]{2}{*}{$\begin{array}{c}\text { Average } \\
\text { value }\end{array}$} \\
\hline & & & & $\begin{array}{c}\text { Average } \\
\text { value }\end{array}$ & & & & $\begin{array}{c}\text { Average } \\
\text { value }\end{array}$ & & \\
\hline SPR-1 & 42.15 & & 42.15 & 41.61 & 59.14 & & 59.14 & 58.22 & 49.48 & 57.71 \\
\hline SPR-2 & 40.88 & & 40.88 & & 57.10 & & 57.10 & & 55.25 & \\
\hline SPR-3 & 43.02 & & 43.02 & & 60.14 & & 60.14 & & 61.97 & \\
\hline SPR-4 & 40.39 & & 40.39 & & 56.50 & & 56.50 & & 64.15 & \\
\hline SPR-1-ST & 35.86 & 6.66 & 29.20 & 30.43 & 50.47 & 8.88 & 41.59 & 43.21 & 90.74 & 94.44 \\
\hline SPR-2-ST & 39.90 & 8.25 & 31.65 & & 55.82 & 10.99 & 44.83 & & 98.13 & \\
\hline OAK-1 & 38.03 & & 38.03 & 38.85 & 53.29 & & 53.29 & 55.09 & 69.89 & $81.5^{2}$ \\
\hline OAK-2 & 38.84 & & 38.84 & & 56.92 & & 56.92 & & 80.36 & \\
\hline OAK-3 & 40.86 & & 40.86 & & 57.27 & & 57.27 & & 87.54 & \\
\hline OAK-4 & 37.66 & & 37.66 & & 52.89 & & 52.89 & & 88.28 & \\
\hline OAK-1-ST & 39.23 & 7.93 & 31.29 & 31.53 & 54.18 & 10.01 & 44.18 & 45.00 & 74.86 & 87.52 \\
\hline OAK-2-ST & 42.73 & 9.77 & 32.95 & & 58.09 & 10.36 & $47 \cdot 73$ & & 83.40 & \\
\hline OAK-3-ST & 39.65 & 8.93 & 30.73 & & 53.78 & 10.04 & 43.74 & & 95.56 & \\
\hline OAK-4-ST & 40.47 & 9.31 & 31.16 & & 55.54 & 11.18 & $44 \cdot 37$ & & 96.24 & \\
\hline SPR & Beams wi & th spruce w & & & & & & & & \\
\hline OAK & Beams wi & th oak web & & & & & & & & \\
\hline -ST & Beams w & th self-tens & oning $\mathrm{d}$ & evice & & & & & & \\
\hline
\end{tabular}

In this range of spans the strictest sizing is usually associated with the limitation of relative deflections. Without the self-tensioning device the solutions with both types of timber product lead to quite similar deflections under service conditions (38.85 $\mathrm{mm}$ with oak and $41.61 \mathrm{~mm}$ with spruce). Under these conditions the greater strength and major cost increase of the oak webs are not justified in practice. On the other hand, when the behaviour of the beams with the self-tensioning system is analysed, the latter was found to be the most effective with spruce webs, practically equalling relative deformations (45.00 $\mathrm{mm}$ with oak and $43.21 \mathrm{~mm}$ with spruce).

Both previous and current studies carried out by our research team have shown an extremely rigid behaviour in all proposed solutions for the flangeweb connection, even in those with the least number of plates. Consequently, it can be concluded that the different density of connections does not compromise the interpretation of the experimental results in relation to the main objective of the analysis.

Moreover, some factors indicate that it is possible to achieve noticeably greater improvements in actual use. This could firstly be achieved by adjusting the dimensions of the interior channel holding the tensioning bar. In an initial phase of this research the said channel was oversize, with the aim of using the different pre- and post-tensioning configurations that were analysed [29]. The $35 \times 85 \mathrm{~mm}$ groove used means that the uniform crosssection was less rigid, $7.4 \%$ less for oak and $7.6 \%$ less rigid for spruce. It is clear that a reduction in the groove dimensions closer to rod diameter (26.5 $\mathrm{mm}$ ) would increase the efficacy of the self-tensioned solution. 
On the other hand, it is important to consider the specific way in which loads are applied. In testing, the values indicated (20 and $28 \mathrm{kN}$ ) were applied in the form of two concentrated forces at thirds of the span. This arrangement is considered to be equivalent to quasi-permanent and total uniform loads (5 and $7 \mathrm{kN} / \mathrm{m} 2$, respectively), although only for the purposes of maximum deflection. On the contrary, the reaction transmitted by each support is very different, and it is $36 \%$ higher in the case of distributed actions in comparison with the application of two single-point loads that are equivalent in terms of deflection. As schematically shown in Fig. 1, the equilibrium conditions in each support lead to the following expression [18]:

$$
\mathrm{N}_{\mathrm{i}}=\frac{2 \mathrm{R}_{\mathrm{i}}}{\tan \alpha_{\mathrm{i}}}
$$

Consequently, an increase in the reaction $\left(\mathrm{R}_{\mathrm{i}}\right)$ produces a greater seating and a smaller angle $\left(\alpha_{i}\right)$. Thus, the tensioning force $\left(\mathrm{N}_{\mathrm{i}}\right)$ and the negative deflection will be greater under uniformly distributed loads than under concentrated forces, in the same proportion in which the reactions increase. Therefore, it can be deduced that the normalized test described above significantly under-values the effectiveness of the system.

\subsection{Self-tensioning force}

The proposed device makes it possible to transform the loads transmitted to the supports into an eccentric tensioning force which in turn redistributes the bending moment along the beam. The effectiveness of this system can be quantified by the load multiplier factor, defined as the coefficient between the self-tensioning force and the reaction in each support for each load value applied. This parameter displayed non-lineal variation during the testing, as each increase in load gave rise to further seating of the support, changing the geometry of the device and thereby the multiplier factor, too [18]. Fig. 8 shows how this factor evolved during the loading process until the estimated service limit was reached.

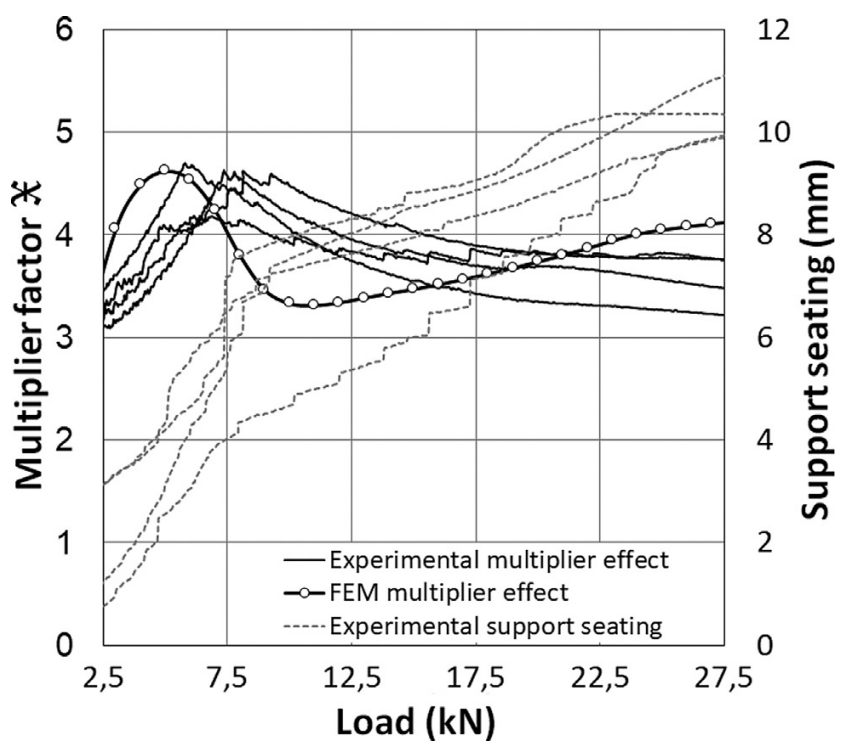

Fig. 8. Multiplier effect (solid lines) and support seating (dashed lines) as a function of the total load applied (European Oak webs). 
The behaviour of this parameter differs noticeably from that foreseen in the said reference, as the theoretical study in the latter involves repeated geometrical analysis that only considers vertical descents and perfect joints. This figure also shows how the support seating evolved. It can be seen that the seating curves of the supports show a certain degree of inflection, which can be interpreted as an increase in the rigidity of the device. This inflection coincides noticeably with a change in the progression of the multiplier, after which its values falls until it almost stabilises.

To study this behaviour numerical analysis was developed using the multibody simulation option from the AnsysTM Workbench platform v.18 (Fig. 9). In the model it is assumed that the wooden parts show elastic-linear behaviour when submitted to tensile forces, and non-linear inelastic behaviour under compression. Stress-strain properties are defined by two different multilinear kinematic hardening models, which are combined with the Hill criterion to simulate the elastic-plastic behaviour of the material.

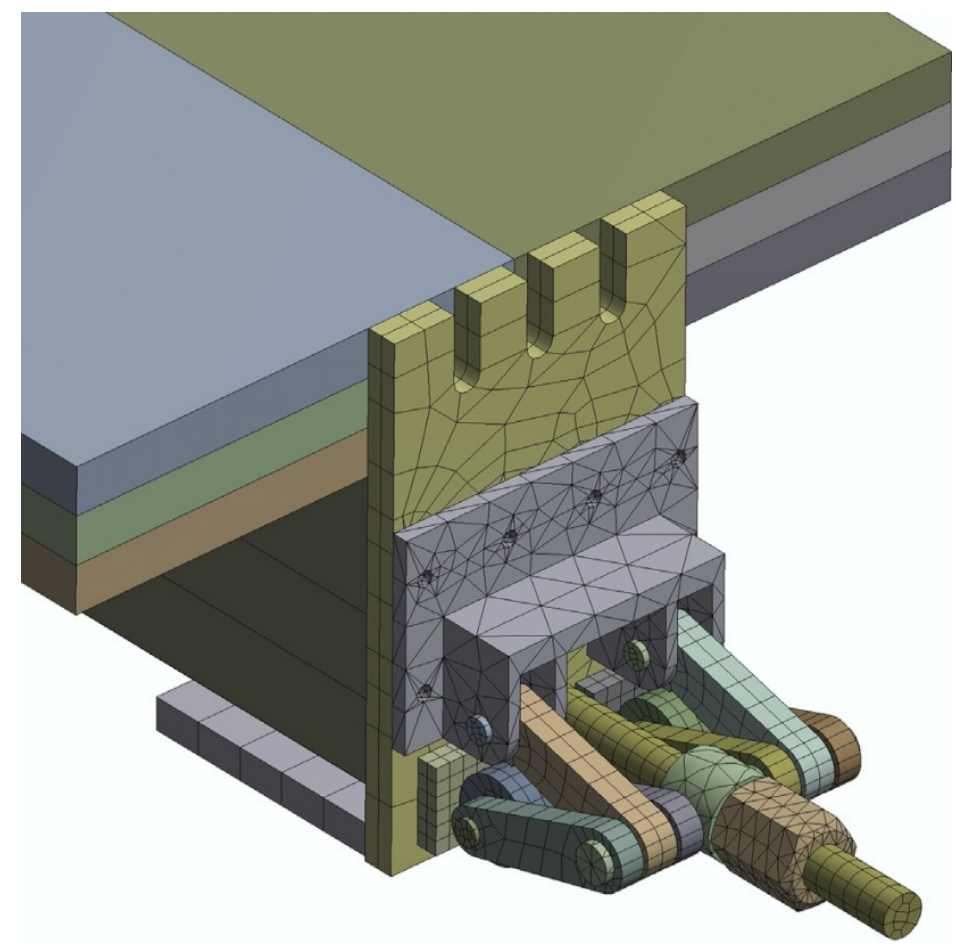

Fig. 9. FEM model. View of the self-tensioning device.

The model reproduces the dynamic behaviour of a system of interconnected bodies with joint elements that allow suitable kinematic constraint of the relative motion between the bodies forming the joint. The model uses MPC184 joint elements, defined by two nodes with 6 degrees of freedom at each node. The kinematic constraints in the joint elements are imposed using the Lagrange multiplier method. The model combines the said joints with CONTA174 to represent contact and sliding between 3D target surfaces (TARGE170), limiting the contact restrictions according to the relative behaviour of the bodies in service in an Augmented Lagrange formulation. Fig. 8 also shows the progression of the multiplier obtained in the model using this strategy, indicating correct correlation with the experimental results. 
The multiplier effect of the device does not therefore display behaviour that is proportional to the loads applied. The study shows a clear dependency of the high contact tensions in the rods and the friction which arises in them. In spite of this, the system is able to transform loads into post-tensioning forces with a noteworthy degree of efficacy. Under service conditions the multiplier tends to stabilise. This leads to a notable fall in deformations of the structure as a whole, as shown in the model in Fig. 10, with a scale factor of 3.0.

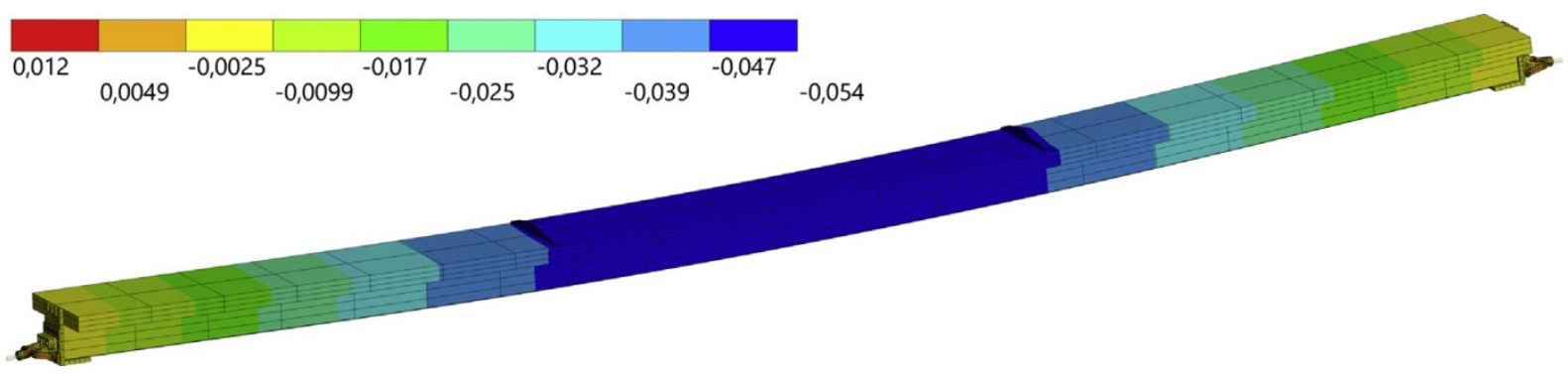

Fig. 10. Deformation of the FEM model with Euopean Oak web in a service situation, scaling up actual values three times (shown in metres).

\subsection{Failure modes and ultimate load}

All of the beams were loaded monotonically up to failure. Only one of them failed due to a split in the connection between the web and upper flange (Fig. 11). This case corresponds to one of the European Oak web beams without self-tensioning system (the second with the greatest final load), which had fewer metal connection plates. In all other cases the fracture started in the tension zone of the web due to excessive tensile stresses in the lower laminations (Fig. 12), with no sign of crushing in the compression zone. In oak web pieces the start of failure coincided with the location of a finger joint in the last laminate, and in the area of the beam between both individual loads. Likewise, in the Norway Spruce web beams the existence of knots in that area led to failure (Fig. 13). Failure was preceded in all of the pieces by cracking noises, which in wood are a typical sign of fibre breakage.

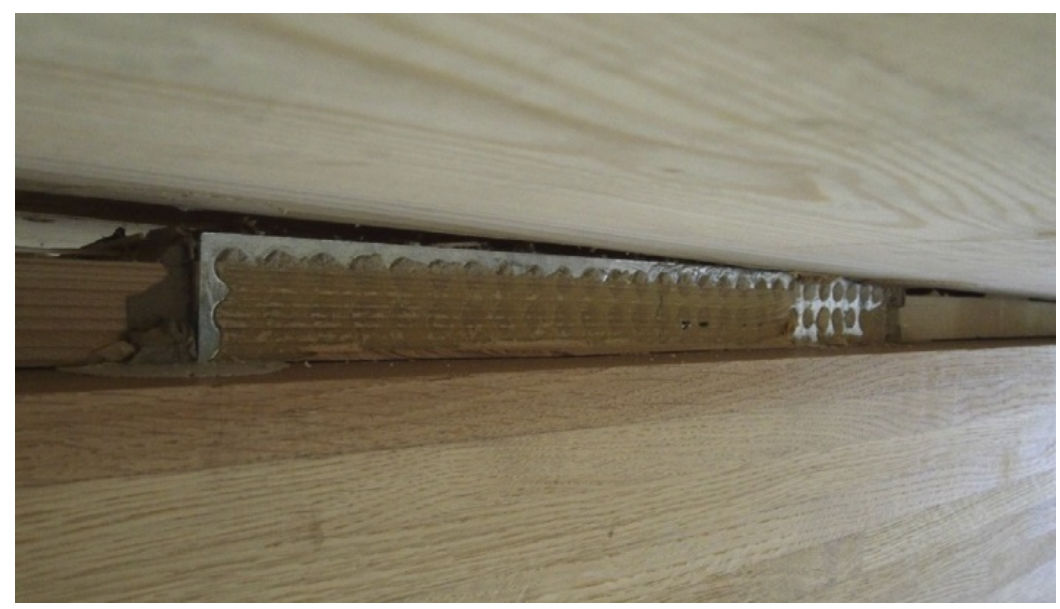

Fig. 11. Failure in the connection between the web and upper flange in a single unreinforced beam. 


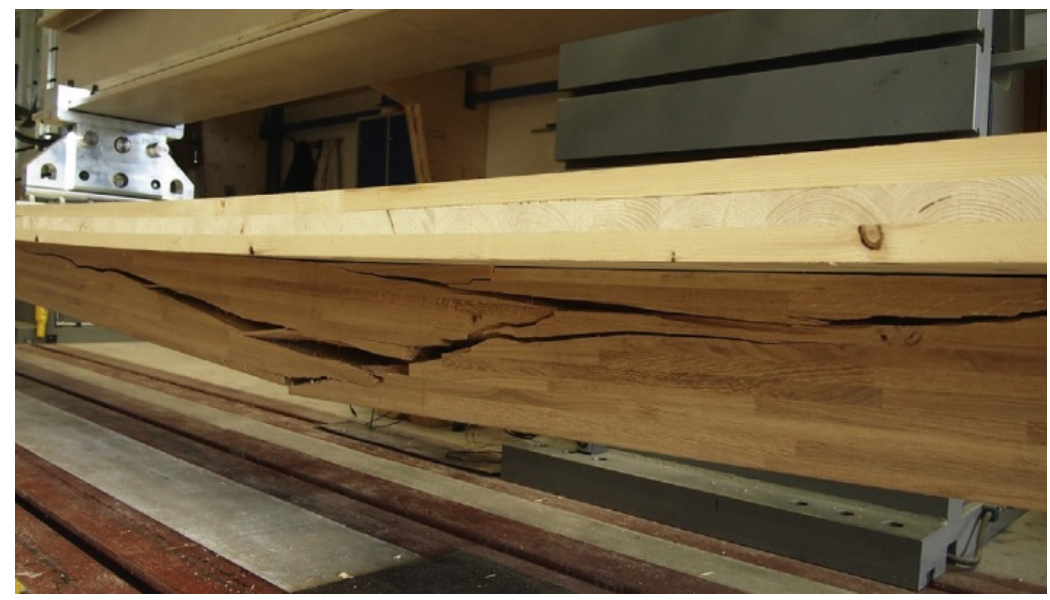

Fig. 12. Typical tensile failure initiated in the bottom laminations of the oak web.

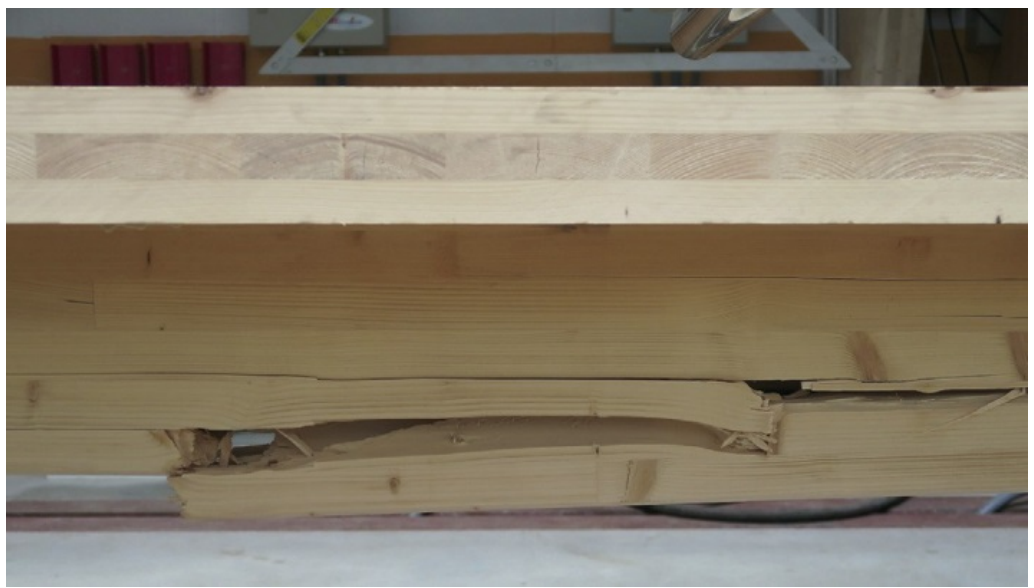

Fig. 13. Tensile failure in the Norway Spruce web due to the existence of knots.

Fig. 14 shows the final load values in the experiment, depending on whether or not the self-tensioning device was used and the type of timber product used in the web. The system made it possible to obtain an increase in the average strength values that was far lower in European Oak (7.36\%) than it was in Norway Spruce (63.63\%). It is therefore considered necessary to increase the number of tests, to achieve statistically significant results.

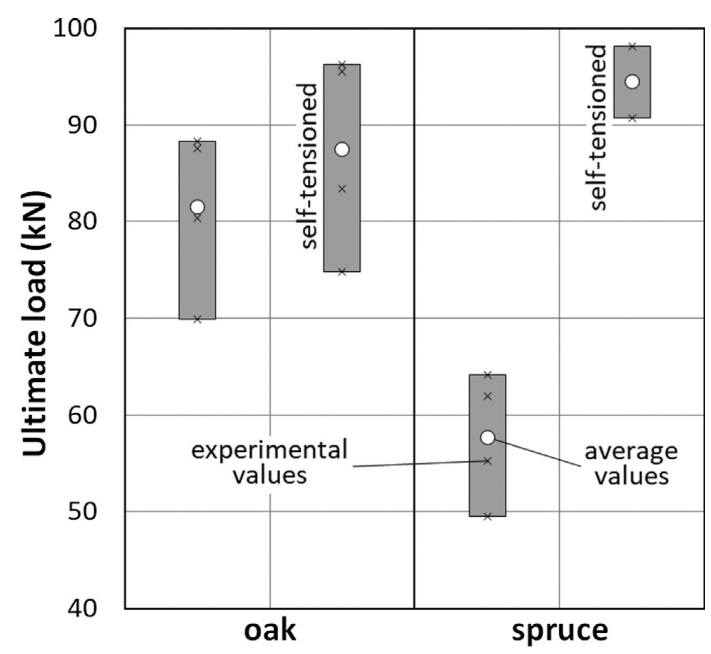

Fig. 14. Comparative graph showing ultimate loads. 


\section{Conclusions}

The system described makes it possible to automatically generate posttensioning forces in beams or floors, depending on the gravitational loads applied on the structure at any given time. These forces act eccentrically respecting the barycentre of the transversal cross-sections, giving rise to a redistribution of bending moments that in turn lead to greater efficacy, especially in terms of deflection.

When in service the proposed system gives rise to an $18.32 \%$ reduction in average relative deflections in the case of European Oak webs, and a 25.78\% reduction with Norway Spruce webs. This difference may increase significantly in real cases due to two factors: firstly by adjusting the dimensions of the groove that holds the rod, as in this study it was oversized to permit different pre- and post-tensioning configurations. The system may also be far more effective when forces are distributed instead of being applied at specific points, as they were in the study. Although the latter were equivalent in terms of deflection, they led to an approximately $36 \%$ weaker self-tensioning force.

Additionally, the self-tensioning device also led to an increase in the loadbearing capacity of the structure, which in average values may be estimated to stand at $7.36 \%$ with European Oak web and 63.63\% with Norway Spruce web.

The proposed system is considered to be especially suitable for use with longspan wooden structural floors. This is fundamentally based on the better behaviour observed in terms of relative deflections, which is directly associated with control of the damage to partition walls. All of the above factors mean that more experimental study is considered to be necessary, to obtain statistically significant conclusions.

\section{Acknowledgments}

This study forms part of a research project entitled "High-performance prefabricated systems of pretensioned wood laminate with non-bonded tendons", financed by the Ministry of Economy and Competitiveness of the Kingdom of Spain and the European Fund for Regional Development.

\section{References}

[1] Gentile C, Svecova D, Rizkalla SH. Timber beams strengthened with GFRP bars: development and applications. J Compos Cons 2002; 6(1): 11-20. http://dx.doi.org/10.1061/(ASCE)10900268(2002)6:1(11).

[2] Issa CA, Kmeid Z. Advanced wood engineering: glulam beams. Constr Build Mater 2005; 19: 99-106. http://dx.doi.org/10.1016/j.conbuildmat.2004.05.013.

[3] Raftery GM, Harte AM. Nonlinear numerical modelling of FRP reinforced glued laminated timber. Compos Part B-Eng 2013; 52: $40-50$. http://dx.doi.org/10.1016/j.compositesb.2013.03.038.

[4] Glisovic I, Stevanovic B, Todorovic M. Flexural reinforcement of glulam beams with CFRP plates. Mater Struct 2016; 49: 2841-55. http://dx.doi.org/10.1617/s11527-015-0690-7.

[5] Yang H, Liu W, Lu W, Zhu S, Geng Q. Flexural behaviour of FRP and steel reinforced glulam beams: experimental and theoretical evaluation. Constr Build Mater 2016; 106: 550-63. http://dx.doi.org/10.1016/j.conbuildmat.2015.12.135. 
E. Martín-Gutiérrez, J. Estévez-Cimadevila, D. Otero-Chans, F. Suárez-Riestra Self-tensioning long-span T-shaped spruce and oak web floors with a CLT upper flange.

[6] Soriano J, Pellis BP, Mascia NT. Mechanical performance of glued-laminated timber beams symmetrically reinforced with steel bars. Compos Struct 2016; 150: 200-7. http://dx.doi.org/10.1016/j.compstruct.2016.05.016.

[7] Corradi M, Borri A. Fir and chestnut timber beams reinforced with GFRP pultruded elements. Compos Part B-Eng 2007; 38: 172-81. http://dx.doi.org/10.1016/j. compositesb.2006.07.003.

[8] Guan ZW, Rodd PD, Pope DJ. Study of glulam beams pre-stressed with pultruded GRP. Comput Struct 2005; 83: 2476-87. http://dx.doi.org/10.1016/j.compstruc. 2005.03.021.

[9] Borri A, Corradi M. Strengthening of timber beams with high strength steel cords. Compos Part B-Eng 2011; 42: 1480-91. http://dx.doi.org/10.1016/j.compositesb.2011.04.051.

[10] De Luca V, Marano C. Prestressed glulam timber reinforced with steel bars. Constr Build Mater 2012; 30: 206-17. http://dx.doi.org/10.1016/j.conbuildmat.2011.11.016.

[11] McConnell E, McPolin D, Taylor S. Post-tensioning of glulam timber with steel tendons. Const Build Mater 2014; 73: 426-33. http://dx.doi.org/10.1016/j. conbuildmat.2014.09.079.

[12] Brunner A, Schnüriger M. Strengthening timber beams with prestressed artificial fibres: the delamination problem. In: Improvement of Buildings Structural Quality by New Technologies. Proc. of the Final Conf. of COST Action C12. Innsbruck, Austria, 20-22 Jan 2005.

[13] Van Beerschoten W, Palermo A, Carradine D, Pampanin S. Design procedure for long-span post-tensioned timber frames under gravity load. In: WCTE 2012 Proc. World Conf. Timber Eng. Auckland, New Zealand, 15-19 Jul 2012.

[14] Newcombe M, Pampanin S, Buchanan AH. Governing criteria for the lateral force design of post-tensioned timber buildings. In: WCTE 2012 Proc. World Conf. Timber Eng. Auckland, New Zealand, 15-19 Jul 2012.

[15] Smith T, Ponzo FC, Di Cesare A, Pampanin S, Carradine D, Buchanan AH, et al. Post- tensioned glulam beam-column joints with advanced damping systems: testing and numerical analysis. $\mathrm{J}$ Earthquake Eng 2014;18:147-67. http://dx.doi.org/10.1080/13632469.2013.835291.

[16] Estévez J, Otero D, Martín E, Suárez F. Self-tensioning system for long-span wooden structural $\begin{array}{llllll}\text { floors. } & \text { Constr } & \text { Build } & \text { Mater } & \text { 2016; } & \text { 102: }\end{array}$ http://dx.doi.org/10.1016/j.conbuildmat.2015.11.024.

[17] Estévez J, Otero D, Martín E, Suárez F. Long-span wooden structural floors with self-tensioning system. Performance under asymmetrical loads. Adv in Mater Sci and Eng 2016; article ID 3696025. http://dx.doi.org/10.1155/2016/3696025.

[18] Otero D, Estévez J, Martín E, Pérez J. Application of a new system of self-tensioning to the design of large-span wood floor framings. J Struct Eng 2016; 142(6): article ID 04016012. http://dx.doi.org/10.1061/(ASCE)ST.1943-541X.0001486.

[19] EN 14080:2013. Timber structures. Glued laminated timber and glued solid timber. Requirements. European Committee for Standardization, Brussels: 2013.

[20] DIN 4074-5:2008-12. Sortierung von Holz nach der Tragfähigkeit - Teil 5: Laubschnittholz. 2008.

[21] ETA-13/o642 (2013) European Technical Approval, "VIGAM-Glued laminated timber of oak". Issued by Austrian Institute of Construction Engineering (OIB), Vienna.

[22] EN 338:2016. Structural timber. Strength classes. European Committee for Standardization, Brussels: 2016.

[23] ETA-14/o349 (2014) European Technical Approval, "CLT - Cross Laminated Timber". Issued by Austrian Institute of Construction Engineering (OIB), Vienna.

[24] EN 1993-1-1:2005. Eurocode 3: Design of steel structures. Part 1-1: General rules and rules for building. European Committee for Standardization, Brussels: 2005.

[25] prEN 10138-4. Prestressing steels - Part 4: Bars. European Committee for Standardization, Brussels: 2000.

[26] EN 10027-1: 2005. Designation systems for steels. Part 1: Steel names. European Committee for Standardization, Brussels: 2005.

[27] EN 408:2010+A1:2012. Timber structures. Structural timber and glued laminated timber. Determination of some physical and mechanical properties. European Committee for Standardization, Brussels: 2012. 
E. Martín-Gutiérrez, J. Estévez-Cimadevila, D. Otero-Chans, F. Suárez-Riestra Self-tensioning long-span T-shaped spruce and oak web floors with a CLT upper flange. An experimental approach

[28] EN 1991-1-1: 2002. Actions on structures. Part 1-1: General actions. Densities, self-weight, imposed loads for buildings. European Committee for Standardization, Brussels: 2012.

[29] Estévez J, Suárez F, Otero D, Martín E. Experimental analysis of pretensioned CLT- Glulam TSection beams. Adv in Mater Sci and Eng 2018; article ID 1528792. http://dx.doi.org/10.1155/2018/1528792. 